\title{
Die Ontwikkeling Van Genetiese Dienste Van Die Departement Van Gesondheid - 1978
}

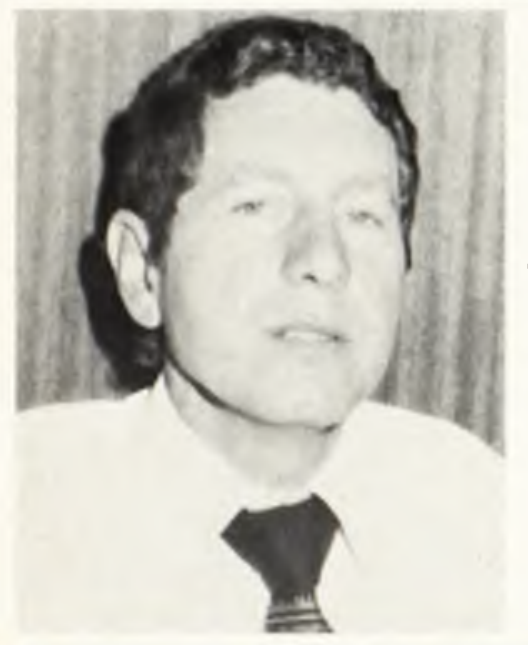

Johann Op’t Hof, B.Sc., B.Sc. Hons., M.Sc., Dr. rer. nat.

\section{SUMMARY}

Genetic Services may be regarded as a new addition to community health services, and are currently in the process of institutionalisation. The provision of this "advanced" health service is long overdue, considering the widespread prevalence of genetic disorders, the rôle of genetic factors in disease in general, the possibilities of prevention, and the devastating implications of congenital and hereditary disorders for the family and community.

The functional activities of the service are based on detection of high-risk and affected individuals, which includes diagnostic investigations and surveillance, genetic counselling and education and training. The nature of the service is outlined with particular reference to the genetics nurse.

Designing a suitable organisational structure and providing essential facilities hallmarked the first phase in the process of institutionalising the service. In the next phase, commencing in 1979 , the service will be implemented more formally with emphasis on evaluation and improvement of the service.

$\mathbf{I}^{\mathrm{N}}$ November 1977 het die Minister van Gesondheid aangekondig dat 'n omvattende genetiese program op nasionale grondslag "nou 'n werklikheid" geword het. Statistieke wat ontwikkelende lande verteenwoordig, is aangehaal om die ems van die probleem van aangebore en erflike afwykings te beklemtoon. ${ }^{1}$

"Een in 40 lewende geboortes het 'n ernstige genetiese afwyking, en tussen 20 en 30 persent van alle toelatings tot pediatriese hospitale is te wyte aan geboortegebreke, aangebore afwykings en siektes, wat direk of indirek na genetiese faktore herlei kan word".

Die Minister net bygevoeg dat die mediese wetenskap die stadium bereik het waar die voordele van navorsing en gevorderde tegnieke " met vrug tot die voorkoming van erflike en aangebore afwykings op gemeenskapsvlak toegepas kan word".

Bestaande genetiese sentra en klinieke het reeds die weg tot genetiese dienste gebaan, in 'n poging om "aan die behoefte te voldoen". Hy het egter bygevoeg dat "bestaande fasiliteite nog ondersteun en uitgebou en veral gekoördineer sal moet word"

"Die uiteindelike sukses van die nasionale genetiese pro- gram berus nie alleen by die owerhede nie, maar ook in die mate van toewyding waarmee die publiek en gesondheidsinstansies hul vrywillige- en ingeligte bydrae wil lewer om 'n beter en gesonder bestaanspeil op individuele, gesins- en gemeenskapsvlak daar te stel",

In hierdie era waar die mens binne perke sy eie toekoms kan beheer, het McKusick in hierdie verband tereg opgemerk "Human genetics is to biology what the atomic theory is to physical science. Human genetics has implications, not only to all aspects of science of man, but to cultural, political and social aspects of human activity"

Groot veranderings neem plaas in die struktuur van ons gemeenskap, wat met veranderende houdings ten opsigte van fundamentele aspekte soos aborsie, bevolkingsbeheer, eugenika en genadedood gepaard gaan.

Dit is bekend dat ' $n$ bevolking se gesondheidstoestand nie alleen aan heersende sosio-ekonomiese toestande van die land verwant is $\mathrm{nie}^{2}$, maar dat die omgekeerde, $\mathrm{nl}$. die uitwerking van gesondheid ook 'n bepaalde uitwerking op die sosio-ekonomiese ontwikkeling het. Dit geld veral vir aangebore en erflike afwykings weens die dikwels kroniese en emstige aard en die effek daarvan op emosies en produktiwiteit. 
DIE INSTITUSIONALISERING VAN DIE

NASIONALE GENETIESE PROGRAM

Die behoefte aan genetiese dienste is reeds by verskeie geleenthede ge-opper ${ }^{3}, 4,5$. Vanweë die voorkomende element aan genetiese dienste verbonde is die noodsaaklikheid vir die diens tot dusver hoofsaaklik uit mediesvakkundige oord beklemtoon.

Met die besef van die behoefte aan so 'n diens en ondersteuning van owerheidsweë, het die proses van institusionalisering egter 'n aanvang geneem. Hiermee word bedoel dat ' $n$ begin gemaak is om die tegnies- en instrumenteel-moontlike implementering van genetiese dienste deur die administratiewe prosesse op te neem vir toepassing binne die raamwerk van gesondheidsdienste.

\section{Genetiese Dienste as funksie van die Wet op Gesondheid, 1977}

Dit is veral met die nuwe Wet op Gesondheid, 1977 (Wet No. 63 van 1977), dat die institusionaliseringsproses van genetiese dienste dan gestalte vind. Sedert met die opstel van die nuwe Wet begin is, het die betrokke Kommissie van Ondersoek van die Wet dit onder andere bevind dat dit "duidelik aangewese was dat 'n stelsel met sentrale beleidsbepaling en koördinering en met uitvoering van dienste op 'n gedesentraliseerde grondslag ontwerp moet word"6.

Met die nuwe Wet "word 'n meer buigsame patroon daargestel waarin die bevoegdhede, werksaamhede en pligte van die verskillende owerhede weerspieël word. Voorsiening word ook gemaak vir die koördinasie van dienste en die daarstelling van gesondheidsbeleid op 'n nasionale vlak sodat die funksies en pligte van die verskillende gesondheidsowerhede aangepas word om beskikbare bronne maksimaal te benut en sodoende die beste gesondheidsdiens aan die publiek te bied." Die pogings van die verskillende owerhede kan dus op 'n kollektiewe basis gekoördineer en gerig word om optimum resultate te verkry.

Ingevolge Artikel 14(a) en 49(a) van die Gesondheidswet van 1977 word onder andere voorsiening vir genetiese dienste gemaak. Alvorens die mate waarin die Wet vir hierdie diens voorsiening maak, illustreer word, kan kortliks eers na die vereistes van 'n omvattende genetiese diens verwys word.

\section{Vereistes van omvattende genetiese dienste}

Die vereistes van ' $n$ genetiese diens is uit die noodsaaklikheid daarvan af te lei na aanleiding van die volgende:

(i) die omvang en aard van aangebore en erflike afwykings ${ }^{7}$,

(ii) die rol van genetiese faktore in siektes in die algemeen, asook ten opsigte van mortaliteit en morbidite $\mathrm{it}^{\mathrm{b}}$,

(iii) die hedendaagse moontlikhede van voorkoming met genetiese dienste vergeleke met slegs 'n paar jaar gelede $^{9}$,

(iv) die implikasies van aangebore en erflike afwykings in gesins-, en volksverband ${ }^{10}$.

Vervolgens kan die vereistes van 'n genetiese diens uit hierdie aanduidings van die noodsaaklikheid vir die diens afgelei, en as volg opgesom word, $\mathrm{nl}$.:

(i) dat persone en/of gesinne en families deur aange- bore en erflike siektes geraak, eerstens opgespoor of geïdentifiseer behoort te word;

(ii) dat ' $n$ proses van bewuswording van genoemde siektes en afwykings aan die publiek en hoë-risiko persone nodig is;

(iii) dat toepaslike opleiding aan gesondheidspersoneel voorsien word;

(iv) dat die beskikbare middele soos diagnoses, vroegtydige behandeling, genetiese raadgewing en ondersteuning aan die betrokke persone beskikbaar gestel word;

(v) dat vanweë die uiteenlopende aard en verskillende fasette verbonde aan genetiese dienste, 'n rasionele diens slegs op 'n omvattende en geïntegreerde basis kan funksioneer, waarby verskillende gesondheidsowerhede, instansies en fasiliteite betrek is;

(vi) en, laastens, dat die diens teen die agtergrond van alle ander gesondheidsdienste evalueer moet word ${ }^{11}$.

Ons sien dus dat die vereistes veelsydig en veelvuldig van aard is wat in besonder koördinasie verg.

Verder is genetiese dienste hoofsaaklik 'n voorkomende en bevorderende gesondheidsdiens. Voorkomende maatreëls wat betref genetiese siektes, is uit die aard van die saak 'n prosedure van keuse wat die bewustheid en gewillige samewerking van die publiek vereis.

Die mate waarin die nuwe Wet op Gesondheid in bogenoemde vereistes voorsiening maak, spruit uit die interpretasie van die Wet wat pertinent plek maar vir:

(i) die klemverskuiwing van bloot kuratiewe dienslewering na primêre en voorkomende gesondheidsorg;

(ii) die benadering van die multidissiplinêre gesondheidspan in gesondheidsorg;

(iii) die benadering van 'n omvattende dienslewering;

(iv) gemeenskapsbetrokkenheid met benutting van eie middele ${ }^{12}$

(v) die meganisme en struktuur om skakeling en koördinasie tussen gesondheidsowerhede en relevante instansies te rasionaliseer ${ }^{13}$.

\section{Die Administratiewe Proses van Institusionalisering}

Die institusionaliseringsproses van genetiese dienste is onder andere ook 'n funksie van 'n bepaalde administratiewe benadering, $\mathrm{nl}$. daardie instaatstellingsbedrywighede wat onderneem moet word om die doelwit wat vir die instelling/diens gestel is te bereik, dit wil sê " "management by objectives (MBO)"'14.

Hierdie instaatstellingsbedrywighede kan in die volgende hoofprosesse ingedeel word:

- beleidbepaling

- organisering

- personeelvoorsiening en -benutting

- finansies

- prosedures en metodes

- beheermaatreëls

In die konteks waarin administrasie volgens doelwit hier gebruik word, kan dit beskryf word "as 'n benadering tot administrasie waardeur ' $n$ stelsel van doelwitte aangewend word om die inspanning van 'n groep werkers sodanig te rig 
dat verdienstelike doelwitte met die spaarsaamste aanwending van die beskikbare hulpbronne bereik kan word"15. Vervolgens sal die verskillende administratiewe prosesse ook hiervolgens gerig wees, bv. wat betref finansies, toekenning van fondse en evaluering sal die doelwitbegrotingstelsel van toepassing wees

Vir die bereiking van die doel met genetiese dienste, $\mathrm{nl}$. om aangebore en erflike afwykings en siektes te voorkom en te beperk, is ' $n$ bepaalde uitvoeringsbeleid, dit wil sê bepaalde funksionele en operasionele bedrywighede nodig elk weer met 'n subdoelwit en verdere mikpunte met hulle respektiewelike organisatoriese (administratiewe) reëlings en programme van aksie.

\section{FUNKSIONELE BEDR YWIGHEDE}

Vier basiese funksionele bedrywighede word in genetiese dienste onderskei, nl.

(i) opsporing en bepaling van hoë-risiko en geaffekteerde persone. Dit sluit in:

* diagnostiese dienste

* waarneming en epidemiologie

(ii) Genetiese raadgewing

(iii) Voorligting en opleiding

(iv) Navorsing

Sonder om op die kwantifisering van subdoelwitte en mikpunte van die verskillende elemente in te gaan, word na elk as volg verwys:

\section{DIAGNOSTIESE DIENSTE}

'n Akkurate kliniese diagnose is 'n vereiste alvorens genetiese raadgewing gegee kan word. Vir hierdie doel maak die klinikus gebruik van bepaalde tekens en simptome wat eiesoortig is vir spesifieke genetiese sindrome. "n Belangrike hulpmiddel in hierdie verband is 'n stamboomgeskiedenis aangesien bepaalde genetiese afwykings soos retinitis pigmentose (wat blindheid veroorsaak) in verskillende families op verskillende wyses oorgeërf word en gevolglik verskil- lende risiko's van herhaling inhou.

In meeste gevalle word die hulp van die laboratoriums ingeroep om 'n diagnose te maak of te bevestig - hetsy van 'n chromosoom-, of biochemies-metaboliese afwyking.

\section{Chromosoomafwykings en aantal ondersoeke gedoen}

Die verwagte voorkoms van chromosoomafwykings by pasgeborenes is ongeveer 1/200 lewende geboortes.

Chromosoomondersoeke is ' $n$ langsame en gesofistikeerde proses wat gespesialiseerde mannekrag vereis. Gevolglik is die koste aan elke ondersoek verbonde van die duurste roetine mediese ondersoeke wat daar is. Besondere oordeel moet ook aan die dag gelê word wanneer 'n chromosoomondersoek aangevra word. Daar is egter bepaalde indikasies wat gewoonlik in chromosoomafwyking aandui.

\section{Indikasies vir chromosoomstudies}

- Bevestiging van 'n vermoede chromosomale sindroom (bv. Down, Turner ens.).

Kinders van ouers wat translokasiedraers is.

- Veelvuldige aangebore afwykings van onbekende etiologie met of sonder geestesvertraagdheid.

- Twyfelagtige eksterne geslagsorgane.

- Dogters met perifêre limfideem

- Kriptorgisme

- Inguinale massa

- Lae reproduktiewe fiksheid - steriliteit, aborsie, voorgeboortelike mortaliteit.

- Geslagschromatientelling wat nie met fenotipiese geslag ooreenstem nie.

- Abnormale geslagschromatien.

Tans is daar agt laboratoriums, elk by een van die groter sentra geleë wat chromosoomanalises ondemeem.

Die aantal ondersoeke in 1977 gedoen* en beraamde aantal vir die toekoms, word as volg saamgevat:

\begin{tabular}{|l|r|rrrr|}
\hline CHROMOSOOMAFWYKINGS EN & JAAR & \multicolumn{4}{|c|}{ VERWAGTE AANTAL } \\
\cline { 2 - 6 } ONDERSOEKE & 1977 & 1978 & 1979 & 1980 & 1981 \\
\hline $\begin{array}{l}\text { Verwagte nuwe geaffekteerde } \\
\text { gevalle/jaar }\end{array}$ & 2700 & 2725 & 2800 & 2850 & 2900 \\
Totale aantal ondersoeke & 3000 & 3500 & 4000 & 4520 & 5000 \\
Aantal ondersoeke < 1 jaar & 700 & 920 & 1150 & 1380 & 1610 \\
& 540 & 720 & 900 & 1080 & 1260 \\
Totale aantal afwykings gevind & 150 & 200 & 250 & 300 & 350 \\
Afwykings < 1 jaar & 390 & - & - & - & - \\
Aantal verwysings vir Downs & 80 & - & - & - & - \\
Aantal Downs < 1 jaar gediag. & 526 & 780 & 1040 & 1300 & 1560 \\
& 15 & 20 & 25 & 30 & 35 \\
Amniosintese gedoen & & & & & \\
Afwykings gevind & &
\end{tabular}


*Persoonlike mededeling van dr A. Retief (Tygerberghospitaal). Die behoefte aan chromosoomondersoeke per jaar word konserwatief bereken op 30000 , waarvan 20000 voorgeboorte ondersoeke en 10000 nageboorte ondersoeke is.

\section{Spesifieke ondersoeke en diagnostiese programme}

Binne die raamwerk van genetiese dienste word bepaalde diagnostiese en ondersoekprogramme van stapel gestuur ten einde hoë-risiko en geaffekteerde persone te identifiseer. Sommige programme word egter nog op ' $n$ loodsbasis behartig.

\section{- Voorgeboortelike ondersoeke vir chromosoomaf- wykings}

Fasiliteite om enige swanger vrou voorgeboortelik vir 'n chromosoomafwyking by die fetus te ondersoek, word as gratis diens beskikbaar gestel waar die risiko vir 'n geaffekteerde baba groter as 1 in 100 is, bv. waar 'n swanger vrou ouer as 40 jaar is.

Toetse vir neuraalbuisdefekte word gewoonlik gelyktydig onderneem. Dit word ook in die vooruitsig gestel om 'n voorgeboortelike siftingsprogram vir neuraalbuisdefekte in te stel.

\section{- Hiperlipidemieprogram}

By die lipiedklinieke in Pretoria en Johannesburg word 'n spesiale program van stapel gestuur vir die vroegtydige opsporing van persone met verhoogde bloedvette ten einde sover moontlik voorkomend (bv. deur middel van dieetterapie) hartprobleme te vermy.

\section{- Neonatale sifting vir metaboliese afwykings}

Die sifting vir metaboliese afwykings by babas in Suid-Afrika is lank uitstaande. In Januarie 1979 het 'n siftingsprogram van hierdie aard in Pretoria 'n aanvang geneem ten einde aminosuurafwykings en hipotiroïdisme vroegtydig op te spoor, met die oog op sekondêre voorkoming.

\section{- Porfirie}

Die blanke bevolking in Suid-Afrika word onder andere gekenmerk deur die hoë voorkoms van Porfirie, veral onder die Afrikaners. Hierdie persone is sensitief vir sonlig en bepaalde medisynes kan vir hulle lewensgevaarlik wees. Gevolglik word gepoog om alle geaffekteerde persone op te spoor, ten einde nadelige gevolge te voorkom. As vertrekpunt word van reeds bekende persone en gesinne met Porfirie uitgegaan. Ondersoeke vir die diagnose van Porfirie word ook as gratis diens voorsien.

\section{- Geestesvertraagdheid}

Onlangs is met sistematiese genetiese ondersoeke by alle Sorg- en Rehabilitasiesentrums en Skole vir Buitengewone Onderwys begin ten einde oorsake van geestesvertraagdheid en ander afwykings te bepaal.

\section{- Alle ander genetiese afwykings}

Wat alle ander genetiese afwykings betref, word diagnostiese ondersoeke as gratis diens deur die Departement van Gesondheid aangebied mits die verwysing deur genetiese dienste behartig is.

Op hierdie wyse word gepoog om persone en gesinne met aangebore en erflike afwykings aan te moedig om vrywillig na vore te kom en sodoende primêre en sekondêre voorkoming te bevorder.

\section{- Die kinderverwysingskliniek}

Voortspruitend uit Genetiese Dienste se kontak met die gestremde kind en sy gesin, het 'n reeds bekende behoefte sterk na vore getree, $\mathrm{nl}$.

(i) die psigososiale ondersteuning aan ouers van kinders met aangebore en erflike afwykings en siektes;

(ii) in die algemeen het ouers van gestremde kinders nie altyd duidelikheid oor waar hulle die een of ander spesiale gesondheidsdiens of inligting kan bekom nie.

'n Geskikte fasiliteit was nodig om in hierdie behoefte te voorsien en wat aansluiting by die genetiese suster se diens kon vind ten einde haar diens omvattend te maak.

So 'n fasiliteit, deur die samewerking van verskeie mediese- en gesondheidsinstansies, is by Munitoria in Pretoria tot stand gebring en staan bekend as die Kinderverwysingsentrum wat voorlopig op 'n loodsbasis bedryf word.

By die Kinderverwysingsentrum is inligting, adresse en direkte kontak met alle moontlike hulpbronne beskikbaar. Daar sal gesondheidspersoneel en ouers met gestremde kinders van watter aard ook al, besonderhede met betrekking tot fasiliteite soos diagnostiek, behandeling, psigososiale ondersteuning, ouergroepe en alle maatskaplike- en gesondheidsdienste, verkry kan word.

\section{VOORLIGTING EN OPLEIDING}

In ' $n$ vroeë stadium is besef dat verskillende teikengroepe eerstens algemeen van aangebore en erflike afwykings en tweedens van genetiese dienste as sulks bewus gemaak moes word, wat ' $n$ bepaalde voorligting- en opleidingsprogram verg.

Voorligting is soos 'n geneesmiddel, 'n operasie of enige ander aard van ingryping. Derhalwe is dit noodsaaklik om op 'n wetenskaplikfundeerde basis eers die positiewe en negatiewe effek van 'n spesifieke voorligtingsaksie te bepaal. Eers wanneer vasgestel is dat die voorligting meer voordele as nadele inhou kan met die voorligting voortgegaan word. Op hierdie wyse kan doeltreffende benutting van middele (fondse) verseker word.

As voorbeeld word die nut van 'n voorligtingsprogram in die VSA oor hipertensie aangehaal*.

* Voorbeeld van gesamentlike studie in VSA oor voorligting vir die voorkoming van hipertensie: 
Groep I

(Voorgelig)

$80 \%$

$75 \%$

ongelukkig

5 dae/jaar

5. Afwesigheid van werk (gemiddeld)

Wat betref genetiese dienste, word in bogenoemde vereiste voldoen deur spesifieke navorsing en opnames oor voorligting en opleiding deurlopend uitgevoer, met die oog op die evaluering en die nodige aanpassing $16,17,18,19$.

\section{Voorligtings- en opleidingsmateriaal}

Gepaste voorligtings- en opleidingsmateriaal in die vorm van brosjures, filıns, strookfilms en skyfies is opgestel en geselekteerd versprei. Die boodskap oor genetiese siektes en genetiese dienste is vereenvoudig en vir benutting op ' $n$ veelsydige wyse, na gelang van behoefte en geleentheid en teikengroep, ontwerp. Die basiese raamwerk van die boodskap is die volgende:-

1. Oorsake van Genetiese Afwykings

- Chromosoomafwykings

- Numeries

- Struktureel

- Enkelgeenafwykings

- outosomaal dominante oorerwing

- X-gekoppeld oorerwing

- outosomaal resessiewe oorerwing

- Multifaktoriale oorerwing

2. Voorkomingsmaatreëls

3. Genetiese dienste

Voorligtingsmateriaal is ook in spesifieke Bantoetale opgestel. In die tydperk 1976 tot 1978 is oor die $100 \cdot 000$ brosjures en opleidingstukke selektief versprei. In dieselfde tydperk is 35 films voortdurend in bruikleen vir vertoning gewees.

In die buiteland was die reaksie op, en belangstelling in die "1977 Perspective on Human Genetics in South Africa" bo verwagting en daarmee is terselfdertyd 'n belangrike medium vir kontakdoeleindes in die buiteland geskep.

\section{Opleiding}

Spesiale kursusse in mensgenetika speel 'n belangrike rol in die opleiding van gesondheidspersoneel, aangesien die vakgebied relatief jonk is en tot onlangs nie sy regmatige plek in leerplanne gehad het nie. Aanbevelings is gemaak om genetika vanaf 1979 op vaste en formele grondslag in die curriculum van verpleegonderrig in te sluit. Dieselfde kan egter nog nie vir geneeskundige opleiding gesê word nie.

Vanaf 1974 tot 1978 is 5 kursusse deur die Departement voldoen. waargeneem. voorgestel word:
Groep II

(Nie voorgelig)

$16 \%$

$72 \%$

gelukkig

$1.5 \mathrm{dae} / \mathrm{jaar}$

van Gesondheid aangebied en 147 verpleegkundiges is opgelei. Die beleid is om in 1979 die formele kursus van 2 weke slegs vir verpleegdosente en genetiese verpleegsters aan te bied en dan in streke gereeld kort kursusse van 2-3 dae aan te bied in ' $n$ poging om in die aanvraag na opleiding te

In 1978 is op spesiale uitnodiging deur die Rhodesia Nursing Association 'n kursus deur Genetiese Dienste in Bulawayo aangebied wat deur oor die 300 gesondheidspersoneel bygewoon is.

Daarbenewens het personeel van Genetiese Dienste van die Departement (hoofkantoor) sedert 1976 'n totaal van 233 uur lesings aan verskeie teikengroepe aangebied en oor die 1400 persone bereik.

\section{EPIDEMIOLOGIE EN STATISTIEK}

Om die opsporing van aangebore en erflike afwykings te bespoedig word geaffekteerde persone en families op ' $n$ vrywillige basis aangemeld. Met behulp van hierdie inligting en die nodige analises kan hoë-risiko persone deur die netwerk van genetiese verpleegsters vroegtydig opgespoor word met die oog op voorkoming en algemene genetiese dienste. Terselfdertyd word die voorkoms van aangebore en erflike afwykings, vir beplanningsdoeleindes en statistiese analises,

\section{VELDWERK EN RAADGEWENDE DIENSTE}

Op 'n vroeë stadium het dit noodsaaklik geword om 'n korps in die lewe te roep wat behulpsaam kan wees met die opspoor van persone wat vir genetiese dienste kwalifiseer en om die diens in die praktyk uit te voer en te ontplooi.

Die aangewese persone vir hierdie doel is spesiaalopgeleide senior verpleegkundiges. Uit hoofde van hulle opleiding is hulle eerstens klinies georiënteerd en tweedens opgelei om 'n koördinerende rol tussen klinici, die publiek/pasiënt en die nodige verwysingsfasiliteite te vervul. Daarbenewens word hulle opgelei om 'n genetiese raadgewingsfunksie te vervul, asook om bystand en psigososiale ondersteuning te verleen.

Die rol van die genetiese verpleegsters asook opleidingsleerplanne word elders breedvoerig behandel ${ }^{19}$.

Skematies kan die rol van die genetiese suster as volg 


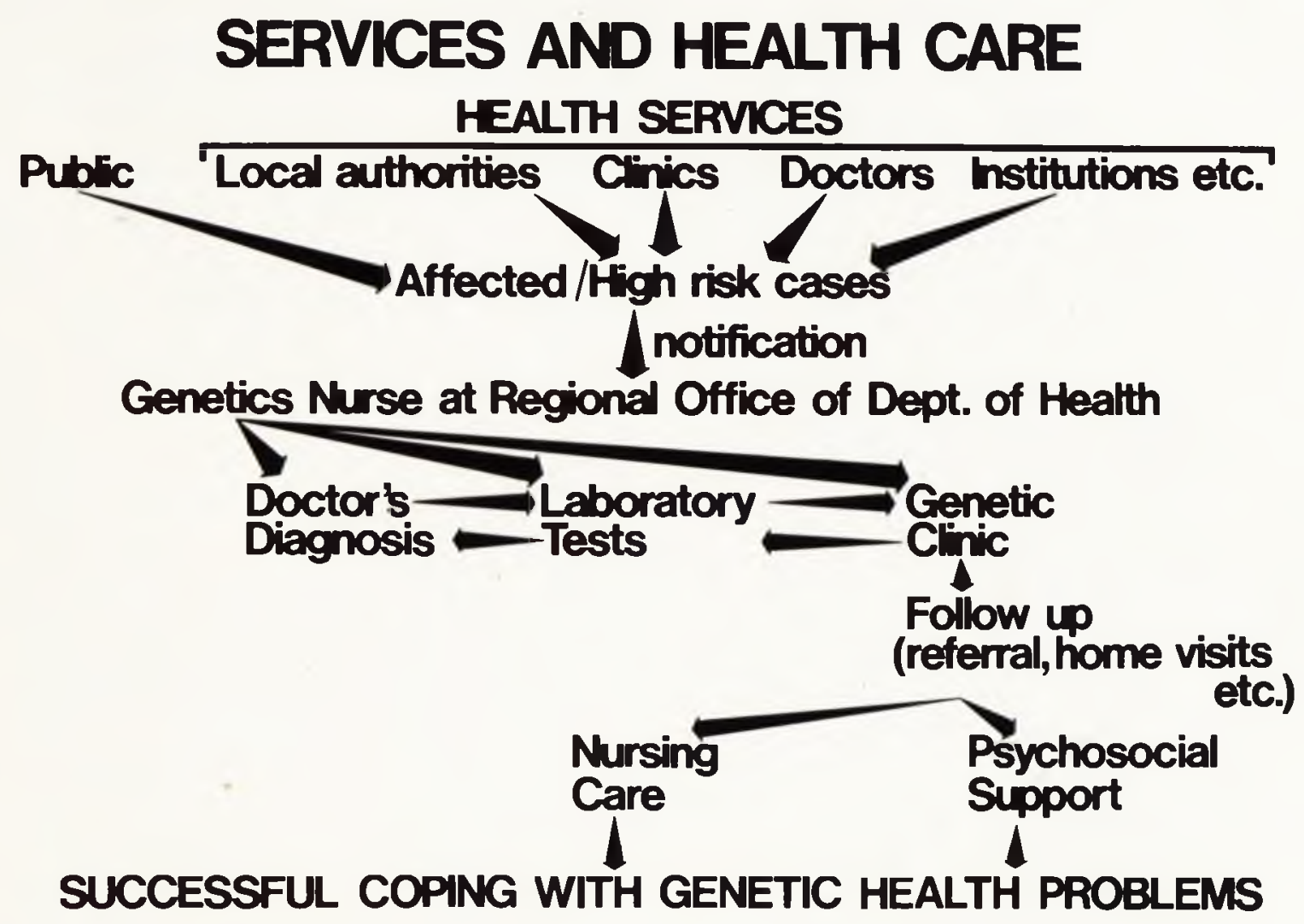

Ten einde in die behoefte aan genetiese susters te voldoen, is by elke Streekkantoor van die Departement van Gesondheid een of meer genetiese susters aangestel wat einde 1978 ten volle met die Provinsiale Administrasies van Oranje-

Vrystaat en Natal se gesondheidsdienste geïntegreer het.

Hulle bedrywighede tot datum word in die volgende tabel saamgevat:

\begin{tabular}{|l|r|r|r|}
\hline WERKSAAMHEDE VAN & & \\
VERPLEEGSTERS IN GENETIESE DIENSTE & 1976 & 1977 & 1978 \\
\hline Aanmeldings & 3620 & 481 & 1266 \\
Verwysing vir kliniese & 1018 & 40 & 789 \\
ondersoeke & 697 & 211 & 222 \\
Chromosoomondersoek laat doen & 150 & 261 & 356 \\
Biochemiese toetse & 1052 & 6000 & 7023 \\
Ander diagnostiek, onder & 105 & 85 & 181 \\
andere siftings & - & 2 & 78 \\
Opvolgings & 130 & 39 & 224 \\
Herbesoeke & 47 & 39 & 91 \\
Raadgewing gedoen & - & - & 57 \\
Verwys vir raadgewing & 44 & 100 & 234 \\
Opvolg na raadgewing & 3 & 4 & 6 \\
Lesings gegee & & & \\
Genetiese Susters in diens & & & \\
\hline
\end{tabular}

METODES VAN VOORKOMING

Uit bogenoemde kan afgelei word dat 'n enkele aktiwiteit of handeling nie 'n effektiewe uitwerking op die voorkoming van aangebore en erflike afwykings sal hê nie, en dat dit nodig is om op 'n wye grondslag en gelyktydig verskillende fasiliteite te mobiliseer om die aanval op die probleem te voer. Metodes van voorkoming sluit onder andere die volgende in: 
- Vroeë opsporing van geaffekteerde persone, hetsy neonataal of later.

- Sifting vir "draers".

- Opspoor en voorgeboortelike diagnose van hoë-risiko babas

- Genetiese raadgewing met die oog op primêre en sekondêre voorkoming

- Toepassing van omvattende genetiese dienste.

\section{Indikasies vir genetiese dienste}

Genetiese raadgewing is een van die belangrikste fasette van genetiese dienste en as eerste stap hiertoe is dit vir die gesin nodig om te besef dat hulle 'n behoefte daarvoor het.

Verder is daar bepaalde indikasies, $\mathrm{nl}$.

- Gesinne met genetiese afwykings, nl.

- tekens wat 'n chromosoomafwyking aandui

- enkelgeen afwykings

- multifaktoriale defekte

- Geestesvertraagdheid

- Individue met 3 of meer aangebore afwykings

- Gesinslede met aanduidings van metaboliese siektes

- Enige siekte of afwyking met familiële voorkoms

- Drie of meer spontane aborsies.

\section{Proses van Genetiese Raadgewing}

Genetiese raadgewing is 'n proses van kommunikasie waarby die genetiese raadgewer die aard van die siekte en die risiko van voorkoms en herhaling asook die implikasies daarvan verduidelik. Sodra die ouers oor die feite beskik bly dit hulle prerogatief om hul eie besluite te neem.

\section{VERWYSINGS}

I. Minister van Gesondheid. Persvrystelling 21 November 1977.

W.H.O. Chronicle. Health population and development 1974, p. 523-528

3. Beighton. P. The Scope of Human Genetics Inaugural Lecture 3rd April (1973), University of Cape Town.

4. Jenkins, T. Prevention of Hereditary Disease S Afr. Med J. 48, 1500 (1974) Op't Hof, J. Preventive Genetics and Community Health S. Afr. Med. J., 47, 299 (1973)

6. Gilliland, J. Gesondheidsdienste en verantwoordelikhede onder die nuwe Wet van 1977. Curationis. Vol. I. No. I p. I0 (1978)

7. Op't Hof, J. Genetic Disease - Risks of occumence and recumence. S.A. Nursing J. Vol. XLIV No. II

8. Emery, A. E. H. Elements of Human genetics. Fourth Ed. Churchill Livingstone, Edinburgh and London (1975)

9. Milunsky, A. The Prevention of Genetic Disease and Mental Retardation. W. B Saunders Company. London. 1975.

10. Kelly, S. Hook, E.B. et al. Birth Defects: Risks and Consequences Academic Press, Inc. N.Y, 1976.

11. Wessex Regional Health Authority U.K. Regional Health Plan. 1978/79.

12. Roux, J. P. Ontwikkeling van Omvattende Gesondheidsdienste in die Selfregerende Swart Gebiede in Suid-Afrika. Curationis. Vol. I. No. 1. p. 30 (1978)

3. Gilliland, J., op. cis. p. II

14. Thomhill, C. Administrasie volgens Doelwit (MBO): ' $n$ Benadering tot administrasie. Die Staatsamptenaar p. 11. Maan 1978

15. Ibid. p. 12

16. Van der Merwe, $C$. Die stand van kennis insake aangebore siektes en afwykings en aanverwante aspekte by blanke vroue in die RSA. RGN-Verslag No. S-N-103 (1977)

17. Van der Merwe, C. Kennis en houding met betrekking tot mensgenetika by 'n groep verpleegsters. RGN-verslag S-N-90 (1977)

18. Van Eeden, A. 'n Kubemeties-gefundeerde voorligtingsprogram vir genetiese dienste. M.A. Tesis UNISA (1977)

19. Nel, L. Die genetiese verpleegster. My Loopbaan. Nov. 78. Vol. 29. Nr. 4 